\title{
Formação de professores nas escolas Wenceslau Braz e Técnica Nacional: o ensino de matemática
}

\section{Formation of teachers in school Wenceslau Braz and National Technical School: mathematical teaching}

\section{Formación de profesores en las escuelas Wenceslau Braz y Técnica Nacional: enseñanza de matemática}

\author{
ARLETE DE JESUS BRITO ${ }^{1}$ \\ Elmha Coelho Moura ${ }^{2}$ \\ ${ }^{1}$ Universidade Estadual Paulista, São Paulo, SP, Brasil. \\ ${ }^{2}$ Universidade Federal da Integração Latino-Americana, Foz do Iguaçú, PR, Brasil.
}

\begin{abstract}
RESUMO
A industrialização brasileira proporcionou o surgimento de uma rede federal de ensino profissionalizante, que ao longo de sua história assumiu diversas denominações. Essas escolas formavam jovens trabalhadores para inseriremse no mercado de trabalho industrial. A falta de professores para atuarem nessas escolas conduziu à criação da Escola Normal de Artes e Ofícios Wenceslau Braz e aos Cursos Pedagógicos na Escola Técnica Nacional (ETN). Este artigo discute os cursos de formação de professores realizados pela Escola Normal de Artes e Ofícios e pela Escola Técnica Nacional e aborda alguns elementos do ensino de matemática praticados nessa formação. Para tanto, foram utilizados documentos do arquivo do Centro Federal de Educação Tecnológica Celso Suckow da Fonseca (CEFET/ RJ), decretos, Boletins da Comissão Brasileiro-Americana para o Ensino Industrial (CBAI) e literaturas referentes ao tema.
\end{abstract}

Palavras-chave: Ensino industrial. Formação de professores. Ensino de Matemática.

\begin{abstract}
The Brazilian industrialization provided the creation of a federal net of professional education that along its history assumed several denominations. Those schools provided courses to form hard-working for the industrial job. But there were no teachers to teach in those courses and this led to the creation of the Normal School of Arts and Crafts Wenceslau Braz and to the Pedagogic Courses in the National Technical School. This article discusses the courses of teachers' formation developed by the Normal School of Arts and Occupations and for the National Technical School and indicates some elements about mathematics teaching in this formation. To elaborate this article we used documents of the archive of the Federal Center of Technological Education Tecnológica Celso Suckow da Fonseca (CEFET/RJ), laws, Bulletins of Brazilian American Commission for Industrial Education (CBAI) and papers about that professional education.
\end{abstract}

Keywords: Industrial education. Formation of teachers. Mathematics Education.

\section{RESUMEN}

La industrialización brasileña ha resultado en la aparición de una red federal para la enseñanza profesional, que a lo largo de su historia tuvo diferentes nombres. Estas escuelas se destinaban a formar jóvenes trabajadores para el mercado laboral industrial. Pero, no había profesores para enseñar en estas escuelas, lo que llevo a la creación de la Escuela Normal de Artes y Ofícios Wenceslau Braz y a los Cursos Pedagógicos en la Escuela de Técnica Nacional (ETN). Este artículo discute acerca de los cursos de formación de profesores desarrollados en a la Escuela Normal de Artes y Oficios y en la Escuela Técnica Nacional e indica algunos elementos de la enseñanza de matemáticas hecha en esa formación. Para elaborar este artigo utilizamos documentos del archivo del Centro de Educación Tecnológica Celso Suckow de Fonseca (CEFET/RJ), leyes, boletines de Comisión Brasileña Americana para la Enseñanza Industrial (CBAI) y literatura acerca del tema.

Palabras clave: Educación industrial. Formación de profesores. Enseñanza de Matemáticas. 


\section{INTRODUÇÃO}

Várias pesquisas têm se voltado à formação de professores realizada em Escolas Normais. No entanto, talvez devido à escassez de fontes, poucas delas problematizam a formação de docentes para o ensino profissional. Até a década de 1960, duas escolas voltaramse a formação docente para o ensino profissional: a Escola Normal de Artes e Ofícios Wenceslau Brás e a Escola Técnica Nacional (ETN). Nesse artigo, pretendemos elaborar um recorte histórico, entre as décadas de 1910 e 1960, sobre a ação formadora de professores de tais escolas e apontar alguns elementos do ensino de matemática nelas realizado.

Em 1834, o Ato Adicional de 12 de agosto, conferiu às Assembleias Legislativas Provinciais a atribuição de legislar sobre a instrução pública, cabendo a elas criar estabelecimentos para promovê-la. Segundo alguns autores (KULESZA, 1998), esse teria sido um estímulo para a criação de Escolas Normais nas Províncias. A primeira Escola Normal foi criada, no Brasil, ainda na época do Império e instalada em Niterói pelo Decreto 10 , de 10 de abril de 1835 . Visava a habilitar professores para o magistério de instrução primária (BRASIL, 1835). Com o passar dos anos, foram instaladas outras Escolas Normais em território brasileiro, como, por exemplo, em São Paulo (1846), Piauí (1866), Sergipe (1881), de modo que, em 1883, já havia vinte e duas em funcionamento. No correr dos anos, os estatutos dessas escolas foram sendo alterados para se adaptar ao contexto social ao qual pertenciam.

$\mathrm{Na}$ área de História da Educação Matemática, várias são as investigações que analisam a inserção da matemática nas Escolas Normais em diferentes regiões do País e em diferentes épocas. Podemos citar, como exemplificação, os trabalhos de Portela (2009), Soares (2013), Oliveira (2015), Souza (2015), Assis (2016) e Rheinheimer (2018). Souza (2015), por meio de entrevistas e documentos escritos, analisa a matemática mobilizada na formação de normalistas, em Belém, entre os anos de 1950 e 1970. Assis (2016) buscou aspectos do ensino de matemática na Escola Normal de Natal, também entre 1950 e 1970 e concluiu que os planos de ensino e material didático dessa disciplina tinham como parâmetros os utilizados em outros estados brasileiros. Oliveira (2015) realiza uma análise do ensino de geometria e de desenho geométrico em Escolas Normais de diversos estados do País, entre 1890 e 1930. Segundo essa autora, nesse período, a geometria euclidiana se consolidou como disciplina escolar, nas Escolas Normais. Portela (2009) analisa a inserção do Movimento da Matemática Moderna (MMM) na formação de normalistas, no Paraná e conclui que o MMM fez parte das atividades que as alunas deveriam aplicar em suas situações de estágio. Soares (2013) investiga as diretrizes que norteavam o ensino de Matemática na Escola Normal da Corte existentes em fins do século XIX. Segundo essa autora, o conteúdo matemático ensinado naquela Escola se assemelhava muito ao exigido em concursos públicos e àqueles ensinados na escola primária. Rheinheimer (2018) enfoca o processo de formação de professores realizado entre as décadas de 1940 e 1955, no Instituto de Educação General Flores da Cunha, em Porto Alegre. Conforme a autora, o movimento escolanovista se fez presente na formação matemática que as normalistas tiveram nessa instituição de ensino.

Como já afirmamos, apontamos tais textos apenas como forma de indicar a diversidade de períodos e de regiões abordadas em pesquisas, na área de História da Educação Matemática, sobre as Escolas Normais, pois, devido a amplos projetos de grupos de pesquisa atuantes na área sobre tal tema, seria impossível realizar uma revisão bibliográfica que esgotasse todos os trabalhos publicados sobre ele em apenas um artigo. Além disso, não é nossa intenção realizar tal levantamento exaustivo, mas sim contrapor o volume de trabalhos sobre as Escolas Normais que formavam professores para atuar no ensino das primeiras letras e sobre aquelas voltadas a formar docentes para a educação profissional. Segundo Urbanetz (2012), das pesquisas produzidas entre os anos 2000 e 2009, disponíveis no portal da CAPES, há 4.695 que abordam a formação de professores, das quais quatro referem-se à formação de professores para a educação profissional.

Em 2006, ocorreu o VIII Simpósio Educação Superior em Debate, com o tema Formação de Professores para a Educação Profissional e Tecnológica. Nos Anais desse evento (2008) encontra-se o texto de Machado (2008) que tratou tal formação a partir de um ponto de vista histórico e refere-se, brevemente, à Escola Normal de Artes e Ofícios Wenceslau Braz e à Escola Técnica Nacional (ETN). Um histórico dessas escolas também é realizado em artigos $^{1}$ de Cunha (2000), Cardoso (2000, 2005, 2013), Souza e Rodrigues (2017) e Meneses Filho e Costa (2017), alguns dos quais abordam o percurso histórico da formação de professores para a educação profissional, no Brasil. Especificamente, na área de História da Educação Matemática, não há qualquer trabalho sobre ensino de matemática desenvolvido na Escola Normal de Artes e Ofícios, segundo busca no banco de teses da CAPES, feita a partir das palavras-chave: Matemática, Escola, Wenceslau; Wenceslau Braz, Matemática; Escola Normal Ofícios, Matemática. Sobre o ensino de matemática na ETN, encontramos o artigo de Moura e Brito (2017), sem menções à formação de professores realizada por essa

\footnotetext{
${ }^{1}$ Dialogaremos com esses textos, no decorrer do artigo aqui apresentado.
} 
instituição. No entanto, a tese de doutorado de Moura (2016) realiza uma breve abordagem na formação de professores da ETN. Assim, a temática da formação de professores no ensino industrial, carece de pesquisas mais aprofundadas.

Assim, o objetivo desse artigo, qual seja, elaborar um recorte histórico sobre a Escola Normal de Artes e Ofícios Wenceslau Braz e sobre a ETN e apontar alguns elementos do ensino de matemática nelas realizado, busca contribuir para o atual debate acerca das Escolas Normais. Para tal, utilizaremos como documentos históricos os boletins da Comissão Brasileiro-Americana para o Ensino Industrial (CBAI), fotos, uma prova de um aluno e decretos. Tais documentos foram encontrados no arquivo da Escola Técnica Nacional, atual CEFETRJ/Unidade Maracanã. No entanto, até o ano de 2015, quando estivemos nesse arquivo, ele sofria inundações do rio Maracanã e, devido a isso, várias caixas de documentos, principalmente relativos à Escola Wenceslau Braz, se perderam.

\section{Escola Normal de Artes e Ofícios WENCESLAU BRAZ}

Em 1909, o Decreto número 7.566 determinou a criação, nas capitais dos Estados da União, de Escolas de Aprendizes e Artífices para o ensino profissional primário e gratuito. Tais escolas seriam mantidas pelo Governo Federal e se destinavam "não só a habilitar os filhos dos desfavorecidos da fortuna com o indispensável preparo technico e intellectual, como fazel-os adquirir habitos de trabalho proficuo, que os afastará da ociosidade ignorante, escola do vicio e do crime" (BRASIL, 1909, p. 1).

Era um momento em que o governo republicano incentivava a nascente industrialização advinda, em parte, da transferência do capital excedente da produção de café para a compra de máquinas e instalação de indústrias. Além disso, a produção de algodão e a modernização de transportes por via férrea deram impulso à indústria têxtil, o que atraiu um grande número de imigrantes para as cidades em que ocorria a industrialização, dos quais muitos se tornaram operários. Porém, condições de trabalho precárias associadas ao aumento do custo de vida nos centros urbanos ocasionaram numerosos e articulados movimentos grevistas pela melhoria de salários. Assim, compreendemos a meta das Escolas de Aprendizes e Artífices em formar trabalhadores disciplinados, ou seja, com "hábitos de trabalho profícuo". Segundo Cunha (2000, p.94) "neste contexto, o ensino profissional foi visto pelas classes dirigentes como um antídoto contra a 'inoculação de ideias exóticas' no proletariado brasileiro pelos imigrantes estrangeiros, que constituíam boa parte do operariado".

Para ingresso nessas escolas de artífices, os candidatos deveriam ter entre 10 e 13 anos de idade e, entre eles, teriam preferência os de menos recursos econômicos. Segundo Cunha (2000), em seu primeiro ano de existência, passaram por essas escolas dois mil alunos. Em seus 33 anos de existência, estudaram nelas 141 mil alunos, com auge em 1920. Vale ressaltar que no período de 1914 a 1918 ocorreu a Primeira Guerra Mundial e, conforme Vaitkunas (2017), esse evento colaborou para o desenvolvimento industrial do Brasil, pois com ele

\begin{abstract}
[...] o comércio internacional sofreu uma queda brusca, afetando toda a economia mundial. No caso brasileiro, o principal efeito desse estrangulamento no comércio internacional foi a queda nas exportações de café, principal produto da pauta de exportações e responsável pelo acúmulo de divisas. Além da impossibilidade de continuar a acumular divisas, a economia brasileira não pode importar uma quantidade significativa de bens de consumo, pois os principais países fornecedores da economia brasileira estavam em guerra.

Com essa mudança significativa de sua balança comercial, o Brasil foi forçado a produzir internamente parte de suas necessidades de consumo (VAITKUNAS, 2017, p. 89).
\end{abstract}

Nesse período, de acordo com CEFETRJ(2007), aliados ao surgimento de um núcleo industrial brasileiro, eram forjadas as principais características da industrialização no País, até o início dos anos de 1930: predomínio da produção de bens de consumo (tecido, vestuário, bebidas, alimentos, móveis), inexistência de indústria de base, dependência de tecnologias importadas e concentração da produtividade na região Sudeste, sobretudo no eixo Rio de Janeiro-São Paulo. Assim, a maioria das escolas da rede federal de ensino profissionalizante do País, localizadas fora desse eixo, antes e após o período 1930, ofereciam cursos muito mais voltados a trabalhos artesanais do que a atividades industriais, tais como o de sapataria, alfaiataria e de marcenaria.

No entanto, não havia mestres de ofícios e professores qualificados para atuarem em tais escolas. Segundo Cardoso (2005), para resolver tal problema, o poder público recrutou professores do ensino primário e mestres de ofícios sem formação pedagógica para atuarem nas Escolas de Aprendizes e Artífices, o que não resultou em uma solução satisfatória, pois,

[...] os professores vindos do quadro de ensino primário não traziam a mínima ideia do que necessitavam lecionar no ensino profissional. Os mestres de ofício, por sua vez, vinham diretamente das fábricas e seriam homens sem a necessária base teórica, a seu favor apenas a capacidade presumida de transmitir a seus discípulos os conhecimentos empíricos (CUNHA, 2000a, p. 80). 
Assim, para formar professores qualificados para atuarem em tais instituições, foi criada no Distrito Federal, por Decreto 1800 de 1917, a Escola Normal de Artes e Ofícios Wenceslau Braz que iniciou seus cursos efetivamente em agosto de 1919. Tinha por finalidade formar professores, mestres e contramestres para os vários institutos e escolas profissionais, tendo, ainda, como objetivo o de preparar professores de trabalhos manuais para escolas primárias municipais.

O nome da escola foi uma homenagem ao presidente da república Wenceslau Brás (1868-1966), reconhecido pela forma como encarava a necessidade de uma escola com tal finalidade. Tal governante, em seu manifesto de 1914 explicita: "Funde a União pelo menos um Instituto que se constitua um viveiro de professores para as novas escolas a que me referi". O Presidente da república compareceu no ato inaugural da Escola, acompanhado de autoridades como o Cardeal Arcoverde (1850-1930) e o Prefeito Amaro Cavalcanti (1849-1922) (FONSECA, 1961, p. 582-583).

Era uma escola mista, sob regime de externato e oferecia cursos profissionais, curso de adaptação e trabalhos manuais. A seção feminina começou a funcionar em 1921 e, até 1937, o número de alunas superou o de alunos, em todos os anos de existência da escola.

O corpo docente da Escola Wenceslau Brás, segundo Fonseca (1961, p.596), era constituído de excelentes professores, uma "verdadeira elite do magistério". Mas, segundo esse autor, a sua finalidade de formar principalmente mestres e contramestres para oficinas escolares, foi "deturpada" pela predominância de moças matriculadas nos cursos destinados a elas. Essa situação que não favorecia a Escola que, por isso, foi alvo de diversas críticas. Por esse motivo, ela teria sido considerada como "elefante branco", pelo então Prefeito da cidade Paulo Frontin (1860-1933), decidido a fechar a Wenceslau Brás. Segundo Fonseca (1961), para conciliar os interesses de Frontin e dos defensores do educandário, o estabelecimento foi transferido em 1919, do âmbito municipal para a esfera federal. Assim, teriam sido conciliados os interesses, pois a falta de professores era um problema de caráter nacional.

Para ingressar na Escola, havia uma prova escrita, com ponto sorteado, como observamos na Figura 1, de questões de português e de aritmética. Os candidatos deviam obter nota mínima de 4 , nos exames.

Pela prova analisada, observamos alguns conhecimentos matemáticos exigidos dos candidatos aos cursos. A primeira questão exige o conhecimento de operações com racionais na forma fracionária e simplificação de frações que pode ser resolvida a partir de um conhecimento das regras operatórias. A pessoa que concorria à vaga indica saber como simplificar frações e também que essa era a questão mais difícil da prova, já que foi deixada por último. A segunda questão aborda juros simples, simplificação de frações e fração como operador ( $1 / 3$ do ano é igual a 4 meses) em sua solução foi aplicada uma fórmula, o que talvez também indique um conhecimento de regras matemáticas. A terceira é uma questão de máximo divisor comum e explicita o método que deve ser usado em sua resolução, qual seja, decomposição em fatores primos. A prova valia 10 pontos e era corrigida por três avaliadores, conforme nos mostra a Figura 1.

Figura 1 - Prova de seleção

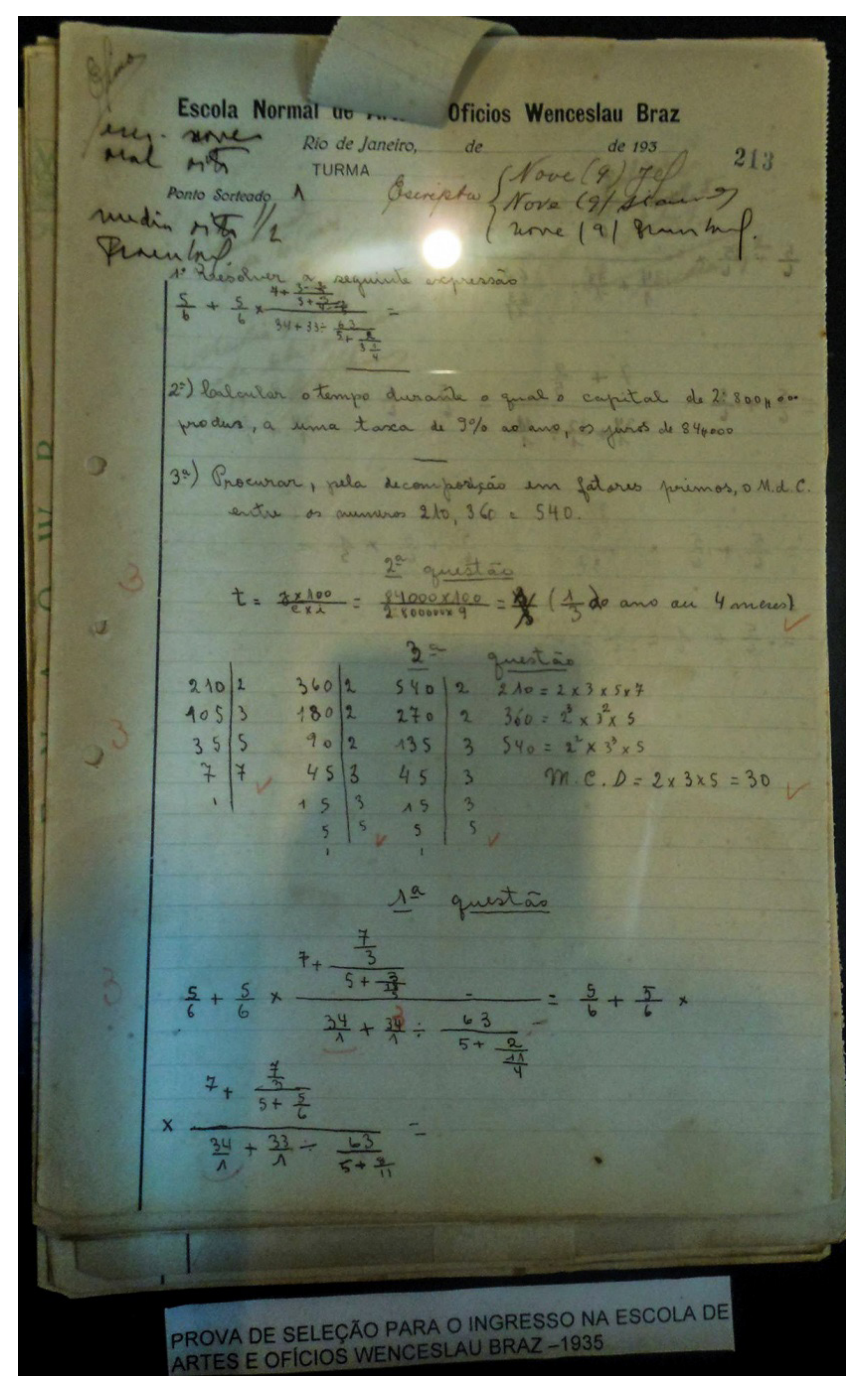

Fonte: Acervo do Centro de Memória/Arquivo CEFETRJ.

Do ano de 1920 a 1929, o número de pessoas inscritas para fazer o exame de admissão saltou de 88 para 297. Em 1920 foram aprovados 24 alunos e 54 alunas. Em 1929, ingressaram na Escola Normal de Artes e Ofícios, 51 alunos e 166 alunas (CARDOSO, 2000). Esses números indicam a crescente participação feminina no mercado de 
trabalho, nas primeiras décadas do século XX, no Brasil. Conforme Cardoso (2005),

As oficinas femininas incluíam o Curso de Trabalhos Manuais e as oficinas de modas, economia doméstica, de flores, de chapéus, de bordados e costura. Além de formar docentes nestas especialidades, a Escola também estimulava que as oficinas produzissem diversos artigos, que eram expostos e vendidos em Feiras de Amostras realizadas na Escola, revertendo a renda para a própria Instituição (CARDOSO, 2005, p. 5).

Na Figura 2, observamos uma dessas Feiras, com a produção dos alunos e alunas da Escola Normal de Artes e Ofícios e etiquetas nos artigos a serem vendidos.

Figura 2 - Feira da produção da Escola Normal de Artes e Ofícios

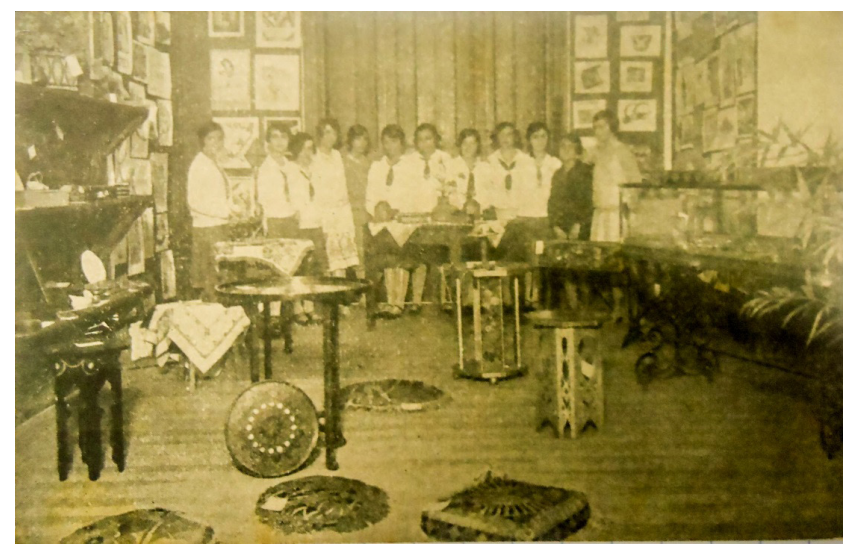

Fonte: Associação de Ex-alunos da ETN/CEFETRJ.

A oficina, cerne do ensino profissionalizante, era um lugar com artefatos, ferramentas e matérias-primas que, em um conjunto de conhecimentos e habilidades reproduzia certos objetos e/ou objetivos, próprios do ofício de cada profissão. As tarefas impostas disciplinavam o corpo a assumir diversas posturas, no manuseio, uso da força e da delicadeza em diferentes técnicas e medidas.

Em 1924, a Escola teve o seu Regimento Interno alterado e deixou de formar contramestres e professores de trabalhos manuais, passando a formar professores e mestres para a educação profissional da União. O currículo, que era de quatro anos, passou a ser de seis, com os seguintes cursos para alunos: trabalhos em madeira, trabalhos em metal, mecânica e eletricidade. As alunas poderiam cursar: economia doméstica, costuras e confecção de chapéus. Havia também os cursos mistos de artes decorativas e atividades comerciais.

Os alunos de todos os cursos deveriam estudar: português e educação cívica, matemática aplicada às indústrias, geografia industrial e história das indústrias, francês, física e eletricidade, química industrial, história natural, higiene, pedagogia, contabilidade industrial, estenografia e datilografia, modelagem e trabalhos manuais, desenho à mão livre e geométrico (CUNHA, 2000a). Segundo Moura e Brito (2017), o ensino de desenho geométrico na formação de artífices e de operários foi defendido desde o século XIX, em diferentes países do mundo. No Brasil, Rui Barbosa (1849-1923) afirmava que o desenho poderia desenvolver hábitos de observação, disciplina mental e de aplicação das faculdades básicas. Moura e Brito (2017) analisam que com o ensino de desenho se buscava educar a "mão e o olho", ou seja, os modos de agir e de observar. Assim, em nosso entender, a inserção de desenho geométrico no curso de formação de professores para a educação profissional visava a fornecerlhes conhecimentos sobre as técnicas de desenho utilizadas em diversas artes e ofícios, mas também colaborar para a formação de hábitos de disciplina.

A relevância da disciplina Desenho era perceptível, também, na distribuição do pessoal docente: professores e adjuntos para as disciplinas. No Regimento Interno da Escola Wenceslau Brás (1926), as distribuições eram em média um professor da disciplina e um adjunto, para dois professores de Desenho e quatro adjuntos, em seguida aparece a Matemática Aplicada às Indústrias com dois professores e um adjunto.

No Regimento Interno da Escola (1926), seriam conferidos diplomas de mestres ao aluno ou aluna que terminasse o quinto ano, os que terminassem o sexto ano recebiam o diploma de professor. Para a obtenção do diploma de mestre e de professor, o aluno deveria submeter-se a uma prova didática.

Segundo Machado (2008), em seus vinte e dois anos de existência, ingressaram na Escola Normal de Artes e Ofícios, 5.301 alunos, mas, nesse mesmo período de tempo, se formaram apenas 381, dos quais 309 eram mulheres, ou seja, ela não estaria atendendo ao objetivo de formar professores para a maioria das escolas técnicas, que eram masculinas. Além disso, a partir da era Vargas, no contexto de nacionalização e criação das indústrias de base, a formação oferecida pela Escola Normal de Artes e Ofícios aos professores da educação profissional não era mais suficiente (SOUZA; RODRIGUES, 2017). Mas, segundo Cardoso (2013), entre os anos de 1924 e 1931, em que Carlos Américo Barbosa de Oliveira, primo de Rui Barbosa, foi diretor da Wenceslau Braz, "observa-se a implementação de práticas educacionais e de gestão escolar baseadas na valorização do desenvolvimento industrial" (CARDOSO, 2013, p. 71). As atividades da Escola Normal de Artes e Ofícios Wenceslau Braz foram encerradas em 1937.

A ação foi pautada pelo artigo 37 da Lei no 378, de 13 de janeiro de 1937, ao determinar que essa Escola 
mantida pela União e as Escolas de Aprendizes e Artífices seriam transformadas em liceus industriais. Para efetivar essa intenção, o Palacete Leopoldina, que abrigava a Escola Wenceslau Brás, foi demolido para ceder lugar à construção de um novo edifício para o liceu.

As obras demoraram cinco anos para serem concluídas, dispersando, assim, o antigo corpo discente feminino da antiga Escola. Antes de ser inaugurado, o novo prédio teve a sua denominação alterada para Escola Técnica Nacional, pois, entrava em vigor a Lei Orgânica do Ensino Industrial, de 30 de janeiro de 1942.

\section{A Escola Técnica Nacional}

A Escola Técnica Nacional (ETN) foi oficialmente inaugurada em 1944, com a presença do então Presidente da República, Getúlio Vargas (1882-1954) e do Ministro Gustavo Capanema (1900-1985). De acordo com Ciavatta e Silveira (2010) estiveram presentes à inauguração alguns professores da extinta Escola Normal de Artes e Ofícioso Wenceslau Braz, além de professores e técnicos recém-contratados: técnicos suíços e norte-americanos selecionados, diretamente, pelo Ministério da Educação e Saúde Pública.

A Lei Orgânica tratava da Reforma do Ensino Industrial que trouxe unidade legislativa em todo território nacional a esse ramo de ensino. As escolas deixavam de pertencer somente ao grau primário para situar-se no secundário.

A nova legislação transformou todas as escolas profissionalizantes federais em escolas do Ensino Industrial, que era dividido em dois ciclos: o primeiro, formado pelo ensino industrial básico (antigo ginasial), e o segundo, ciclo pelo ensino técnico (secundário). A pobreza também deixou de ser critério primordial para os alunos ingressarem nessas novas escolas, tornavase necessário a aprovação no processo de seleção, que considerava como critério primordial os índices de aptidão alcançados nos exames escritos e no psicotécnico.

Ao reabrir as portas como Escola Técnica Nacional, a instituição oferecia os cursos do ensino industrial básico àqueles que tivessem completado o curso primário, e os cursos do ensino técnico àqueles que tivessem concluído o ensino ginasial ou curso industrial básico e mantinha o seu caráter preparatório de pessoal docente e administrativo para esse ramo de ensino.

A Escola ofereceu quinze cursos industriais básicos com duração de quatro anos: Alfaiataria; Aparelhos Elétricos e Telecomunicações; Carpintaria; Cerâmica; Corte e Costura; Chapéus, Flores e Ornatos; Fundição; Marcenaria; Máquinas e Instalações Elétricas; Mecânica de Máquinas; Mecânica de Precisão; Mecânica de Automóveis; Serralheria; Tipografia e Encadernação, e Pintura. Para atender à demanda crescente por cursos técnicos, ocasionada pelo novo processo de industrialização do País, a Escola, segundo CEFETRJ (2007), extinguiu gradativamente os cursos industriais básicos, que tiveram a sua última turma formada no ano de 1964.

No cenário nacional, o projeto de industrialização do Estado Novo (1930-1945) permitiu a construção do parque industrial brasileiro, com a implantação de uma indústria de base moderna - como a Companhia Siderúrgica Nacional (CSN), em 1941; Companhia Vale do Rio Doce, em 1942; Fábrica Nacional de Motores (FNM) e Fábrica Nacional Álcalis, em 1943 - que proporcionou o desenvolvimento econômico do País. Pode-se considerar que foi um verdadeiro surto industrial, em consonância com Lei Orgânica de Capanema, que nutriu as empresas de suficiente e adequada mão de obra, conforme as suas necessidades crescentes e mutáveis.

A ETN ofereceu os seguintes cursos técnicos, com duração de três anos: Construção de Máquinas e Motores, Eletrotécnica, Edificações, Decoração de Interiores, Desenho Técnico e Eletrotécnica, Desenho Técnico de Arquitetura e Móveis, Construção de Aeronáutica. Em 1959, a Escola ampliava de três para quatro anos de duração os seus cursos técnicos, com essa reformulação curricular, passou a oferecer ao invés de sete, seis cursos: Eletrônica, Edificações, Estradas, Máquinas e Motores e, Meteorologia.

A participação feminina nos cursos técnicos e industriais era alavancada a novos patamares, conforme menciona no artigo 3을 do Decreto-Lei no 4.073:

$\mathrm{O}$ direito de ingressar nos cursos industriais é igual para homens e mulheres. A estas, porem, não se permitirá, nos estabelecimentos de ensino industrial, trabalho que sob o ponto de vista da saúde, não lhes seja adequado (BRASIL, 1942).

Assim, as jovens estudantes matricularam-se nos diversos cursos oferecidos e compartilharam com os rapazes os espaços das oficinas. Como podemos observar na Figura 3.

A Escola Técnica Nacional, pela Lei Orgânica do Ensino Industrial, formou artífices, mestres e técnicos para as indústrias, porém, encontrou dificuldades de colocar em funcionamento os Cursos Pedagógicos, destinados à formação de pessoal docente. A legislação previa a implantação desses Cursos em duas modalidades de ensino: Didática do Ensino Industrial e Administração do Ensino Industrial, ambos tinham a duração de um ano. Esse curso foi implantado somente em 1954, mas a Escola sempre manteve a sua função de qualificar professores para o ensino industrial, oferecendo uma variedade de cursos de aperfeiçoamentos como os Cursos Avulsos, Cursos Extraordinários de Especialização e os Cursos de Férias. 
Figura 3 - "Seu tempo sua história: 90 anos de formação profissional"

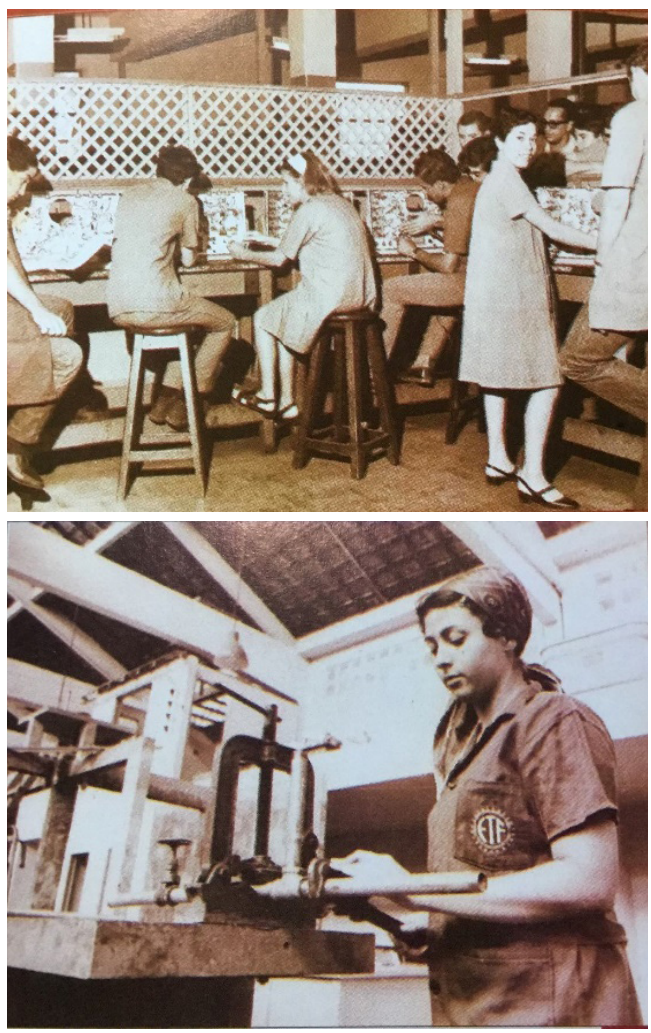

Fonte: Livro do CEFETRJ (2007).

Para o Curso Pedagógico, de 1954, houve 59 alunos inscritos, dos quais 33 eram do sexo feminino, que conquistaram as 15 bolsas oferecidas pelo curso.

A Escola ministrou também o Curso Extraordinário de Especialização para a Petrobrás, destinado, à formação de pessoal técnico do terminal da Guanabara (TEGUÁ). A finalidade era ampliar os conhecimentos dos trabalhadores diplomados, bem como dos professores de disciplinas de cultura técnica ou de cultura pedagógica, incluídas no curso industrial. O Curso tinha como disciplinas fundamentais: a Matemática, a Física e a Química.

Com o intuito de remediar a falta de formação de professores para o Ensino Técnico, a Comissão BrasileiroAmericana de Educação Industrial (CBAI) instituiu uma série de cursos e aperfeiçoamento destinados ao aprofundamento dos conhecimentos do professorado já atuante nas escolas industriais. Esses cursos, apesar de úteis, não substituíram a finalidade dos Cursos Pedagógicos.

\subsection{Cursos de Férias da CBAI}

A Comissão Brasileiro-Americana de Educação Industrial (CBAI) foi criada com a finalidade de estabelecer melhorias na educação industrial brasileira, decorrente da dificuldade de contratar professores qualificados para as disciplinas de cultura técnica. Era um órgão executivo de um acordo firmado entre o Ministério da Educação e Saúde e a Education Division do 'Institute of Inter-American Affairs' (MOURA, 2016).

No início de 1947, seguiu para os Estados Unidos, segundo Fonseca (1961), a primeira turma de professores do ensino industrial, com finalidade de aperfeiçoamento nas diferentes técnicas que ensinavam. Era um grupo de quarenta docentes das disciplinas de oficinas, de diversas escolas da rede federal. O curso possuía duas etapas. $\mathrm{Na}$ primeira, os professores selecionados concentravam-se na Escola Técnica Nacional, para revisar conteúdos de conhecimentos gerais e técnicos, estudo da língua inglesa e atualização e ampliação dos conhecimentos sobre a vida social no Brasil. Na segunda etapa, aconteceria nos Estados Unidos uma espécie de estágio: a permanência era de um ano, estagiando seis meses em escolas profissionais, três meses nas indústrias para se aperfeiçoarem nos ofícios, e três meses frequentando um curso pedagógico. No retorno ao Brasil os professores-alunos escreviam suas experiências profissionais no Boletim da CBAI.

Outros cursos foram ofertados pela CBAI durante o período não letivo, para os docentes, os chamados Cursos de Férias. De frequência anual, esses Cursos eram realizados nas capitais: Rio de Janeiro, São Paulo, Porto Alegre e Recife. Essas cidades eram consideradas pontos estratégicos para o deslocamento dos professores das diversas escolas técnicas e industriais do País.

Os Cursos de Férias, segundo CBAI (1951), tinham como objetivos melhorar os processos e métodos de ensino empregados pelos professores de cultura técnica; ampliar, aprofundar e atualizar os conhecimentos desses professores, nas disciplinas que lecionavam; despertar e manter nos professores o desejo de se aperfeiçoar, de melhorar cada vez mais seus métodos de ensino e de fundamentar a sua ação educativa nas práticas recomendadas pelas ciências da educação.

As atividades desenvolvidas nesses Cursos dividiam-se em teóricas, práticas e de visitas. Essa última era destinada a observação do funcionamento de máquinas, de laboratórios, de produções e das atividades próprias das indústrias, das empresas e das escolas de ensino industrial.

Desses cursos, vamos descrever, com mais detalhes, o Curso de Férias realizado na cidade do Rio de Janeiro em 1952. Para isso, tomaremos como documento o Boletim da CBAI (1952). Esse curso teve capacidade para 30 docentes, 17 desses para o ofício de madeira (Marcenaria e Carpintaria) e 13 para o de Metal (Mecânica de Máquinas, Serralheria e Solda). Com duração de sete semanas, foram ministrados cursos sobre Metodologia do Ensino Industrial; Organização de Séries Metódicas e revisão de conteúdo. As visitas programadas aconteceram em indústrias de São Paulo e do Rio de Janeiro. 
As disciplinas aconteciam em sessões de 2 horas, no mínimo (CBAI, 1952). Assim, havia as disciplinas com uma sessão: Introdução ao curso de Metodologia; Como aprendemos; A demonstração; A exposição oral; Perguntas no ensino; As demais técnicas do ensino (discussões, visitas, experiências, execuções etc.); Motivação da Aprendizagem; Plano de aula - A aula propriamente dita; Tarefas e aplicações do Aprendizado; O ensino individual e o ensino em grupo; As folhas de instruções (uso); e a revisão da Matéria estudada. Havia também disciplina com duas sessões, ou seja, A orientação da aprendizagem de habilidades, e com três sessões: Auxílio visual, e Avaliação do registro do processo do aprendizado.

Com base nesse programa, os professores-alunos realizaram trabalhos práticos de demonstração, de ministrar uma aula completa, desenvolver um trabalho prático, preparar um auxílio visual, elaborar um teste de cada tipo, além de ler artigos, resumos e compêndios.

Havia orientação para que os docentes elaborassem os seus planos de aula, além de questões direcionadas à aprendizagem do aluno, à motivação dos estudantes por meio de discussões, à visitas técnicas, experiências no futuro campo profissional, ao desenvolvimento de atividades individuais e em grupos, revisão geral dos conteúdos e ao uso de auxílios visuais, de maneira a considerar as perguntas realizadas em sala de aula por seus futuros alunos. Segundo o Curso, para obter êxito no processo de ensino e aprendizagem era preciso que o professor utilizasse corretamente os instrumentos necessários à avaliação e ao registro do progresso dos alunos.

O curso Organização de Séries Metódicas e revisão de conteúdo trazia o nome de um método pronto e sistematizado de atividades oficinais de desenhos a serem realizadas pelos alunos com orientação do professor e tinha o seu uso destinado às oficinas escolares da rede federal. $\mathrm{O}$ programa era composto de teorias e práticas do ofício, com questões referentes a máquinas, equipamentos, processo de trabalho e seus métodos de ensino. O Curso enfatizava as questões referentes ao ofício e oficinas, com o uso adequado dos materiais destinados à Série Metódica, em seu uso, registro e processo de avaliação. Os professoresalunos realizaram trabalhos práticos destinados ao uso adequado das Séries Metódicas nos ofícios.

Os cursos de Solda, Madeira e de Máquinas e Motores eram de caráter essencialmente práticos, razão pela qual muitos dos cursos aconteciam em fábricas e oficinas industriais e/ou realizavam visitas técnicas, em locais como: White Martins S. A., Arsenal da Marinha, Companhia Siderúrgica Nacional, Companhia Good Year, Escola "Roberto Simonsen" do SENAI, General Motors do Brasil, Elevadores Atlas S.A., Núcleo do SESI, Estamparia Caravelas, Companhia Progresso Industrial do Brasil.
Os Cursos de Férias também atendiam os professores de Desenho Técnico, com um programa em que, segundo CBAI (1950), constava Revisão de Conteúdos, Metodologia, Fundamentos de Educação e, ainda, Trabalho em Oficina. Atendiam também, aos professores de Ofício nas seções de Metal e Madeira, com um programa de Aplicação Matemática, Desenho Técnico e Tecnologia do Ofício. A Matemática e o Desenho, segundo Moura (2016), contribuíam para a execução de projetos, as tomadas decisões e as escolhas no trabalho técnico, repleto de normas, códigos, símbolos e linguagem.

No cartaz da Escola Técnica Nacional (1960) (Figura 4), a frase "O Brasil precisa de PROFÊSSORES", afirmava a necessidade de docentes qualificados e indicava o Curso de Treinamento de Professores para o Ensino Industrial, que se realizaria na cidade de Curitiba, em 1961. Nesse ano, a cidade já abrigava o Centro de Pesquisa e Treinamento de Professores, sob os cuidados da CBAI.

Figura 4 - Cartaz da ETN (1960)

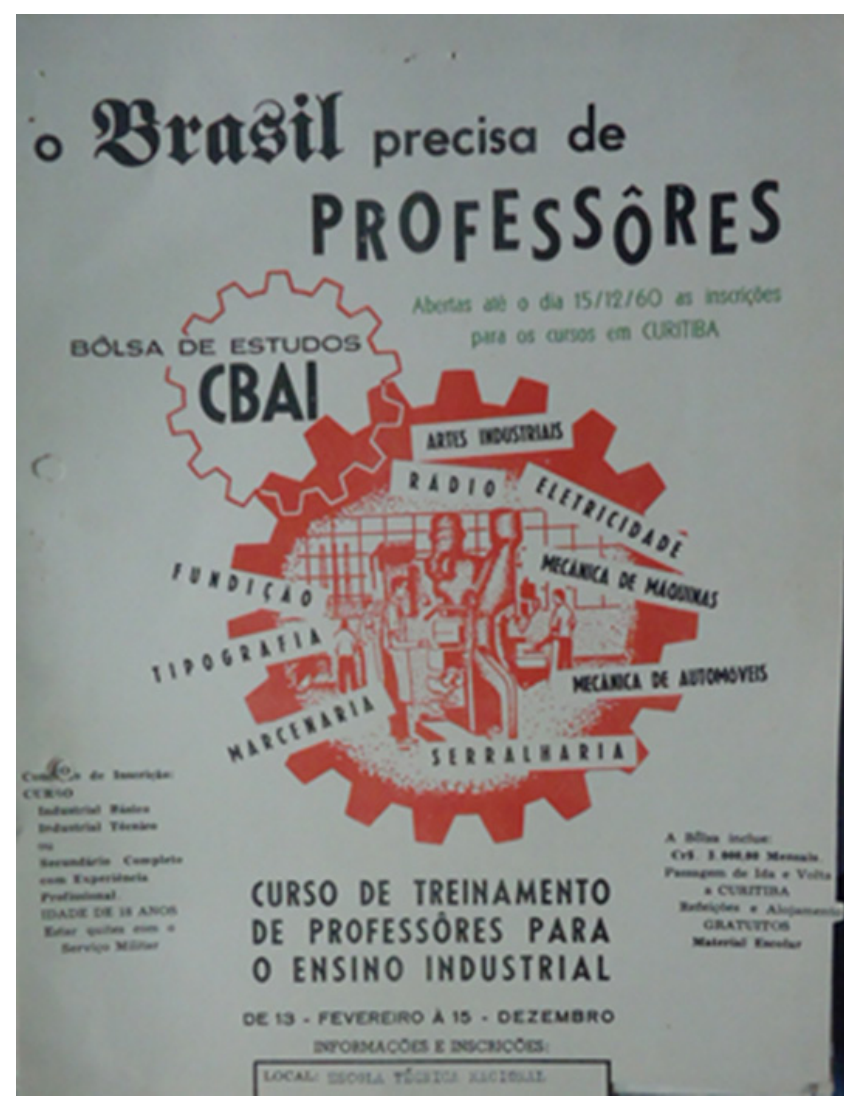

Fonte: Acervo do Arquivo do CEFETRJ/Arquivo Geral, Fundo ETN, cx. 61.2.2.

A Comissão oferecia bolsa de estudos, passagens de ida e volta, alojamento, refeições e material escolar gratuito para os cursistas. Esses deveriam ter a idade mínima de 18 anos e o curso industrial básico, industrial técnico ou secundário completo com experiência profissional. Os 
cursos oferecidos eram: Fundição, Tipografia, Marcenaria, Serralheria, Mecânica dos Automóveis, Eletricidade e Radio, com duração de 10 meses.

Os Cursos de Férias eram de grande valia para o aperfeiçoamento dos professores das disciplinas de cultura técnica, porém a crescente demanda por esses profissionais - mesmo com as formações realizadas dificultava a contratação e o preparo de professores em números suficiente para lecionar nas escolas federais.

\subsection{Os Cursos Pedagógicos}

Uma solução prevista para suprir a falta de professores, qualificados a atuar nas disciplinas de cultura técnica, estava presente na Lei Orgânica do Ensino Industrial, com a criação dos Cursos Pedagógicos. A dificuldade de implantação foi um grande desafio encontrado pela ETN, que solicitou, segundo Fonseca (1961), por diversas vezes, recursos necessários à execução do que a Lei determinava. Essa situação se contrapunha a uma realidade nacional de crescimento industrial e de consolidação da rede federal de ensino profissional no país.

A criação de um parque industrial brasileiro, na década de 1940, com a implantação de indústrias de base, que possibilitou também o desenvolvimento do setor automotivo, na década de 1950, são exemplos de crescimentos que impulsionaram a construção civil, aberturas de estradas, ampliações de linhas de telégrafos, entre outras. Em consonância, as escolas técnicas e industriais brasileiras ofereciam cursos para atender um mercado industrial crescente. Assim, a necessidade de cursos de formação de professores para o ensino industrial tornava-se imprescindível.

Foi somente em 1954, pelo decreto no 36.268 , que a Escola Técnica Nacional passou a oferecer o Curso Pedagógico, na modalidade Didática do Ensino Industrial, a ser ministrada em quatro disciplinas distribuídas no período de um ano. Tais disciplinas agrupavamse em "termos". De acordo com o plano descrito no mencionado decreto, no $1^{\mathrm{o}}$ termo constava as disciplinas de Princípios de Psicologia Educacional, Orientação Educacional e Profissional, História da Educação e História do Ensino, e Análises de Ofícios. Seguiam as disciplinas do $2^{\circ}$ termo com Prevenções de Acidentes; Rodízio Vocacional; História, Objetivos e Organização do Ensino Industrial; Métodos no Ensino Industrial. As do 3 o termo contemplavam: Elaboração de Material Didático; A Integração Psicológica nos Currículos do Ensino Industrial e Avaliação do Aproveitamento na Oficina; Desenvolvimento da Indústria no Brasil e no Mundo; e Organização e Direção de Oficina. Por fim, no 4 o termo havia Prática de Ensino.

Era um programa organizado sob os alicerces educacionais da psicologia, história, metodologias de ensino e, ainda do ofício, com características próprias do ensino industrial. Esses elementos justificavam os critérios exigidos no processo de admissão dos professores aprovados, que deveriam ter concluído o curso de engenharia, ou química industrial, no nível técnico ou mestria. O professor deveria também ter trabalhado na indústria durante três anos no mínimo e ter sido aprovado no vestibular. Era o perfil de um profissional com formação e experiência em seu campo de ofício. Assim, entendiase que lhe faltava apenas o Curso de Didática para que fosse qualificado pedagogicamente, tornando-o apto a lecionar na rede federal de ensino profissionalizante, com o diploma de licenciado.

Para os profissionais que desejassem fazer um curso de didática, mas não tivessem concluído um dos cursos supracitados e fosse portador de diploma de qualquer ensino de segundo grau, o decreto $\mathrm{n}$ - 36.268 previa os Cursos Avulsos de Didática do Ensino Industrial. Para esses candidatos, o exame de seleção compreenderia provas escritas de Português e Matemática em nível do curso industrial básico, de Tecnologia e Leituras de Desenho nas áreas correlatas do candidato; Prática de Ofício; e entrevista profissional. Os alunos que se matriculassem no Curso ficavam sujeitos ao estudo de Português, Matemática, Desenho Técnico, Tecnologia, além das disciplinas regulares anteriormente mencionadas. A esses era conferido o diploma de habilitação.

Segundo Moura (2016), a Matemática e o Desenho constituíam a base de um conhecimento aplicado às técnicas do ofício, essas essenciais para a formação do professor das disciplinas de cultura técnica. A Matemática, no ensino industrial, permitia desenvolver $\mathrm{o}$ pensamento focalizado com o raciocínio rápido $\mathrm{e}$ eficaz nos seus fazeres; compreender e realizar os padrões de exatidão relacionados com as escolhas e os procedimentos corretos; desenvolver a crítica em relação aos números, os quais podiam indicar o êxito e os erros das atividades; compreender e calcular os erros permitidos, no seu limite aceitável e, por fim, desenvolver o pensamento geométrico, necessário para compreensão e desenho dos objetos. Em consonância, tais capacidades eram requeridas nas atividades de Desenho e para tanto era essencial desenvolver a percepção espacial e modos de expressão gráfica correta do mundo visível; a sensibilidade na aplicação de padrões de exigências e a comunicação na elaboração de avaliações críticas de forma a agir e reagir com responsabilidade, perante os desafios de sua profissão e condicionantes sociais.

A legislação impunha que os Cursos Pedagógicos e os Cursos Avulsos pudessem ser ministrados em caráter experimental pela CBAI e cabia às instituições de ensino, no caso a ETN, realizar as matrículas e estabelecer o regimento escolar. 
Segundo Fonseca (1961), esse decreto de 1954 revestia-se de grande importância por estabelecer normas mais eficientes para o preparo do magistério do ensino industrial, pois a falta de professores para esse tipo de ensino era um problema que continuava a ter quase a mesma gravidade dos primeiros tempos da implantação daquele tipo de educação. Porém, os desafios continuaram a existir, uma vez que as condições de matrículas dificultavam a procura dos Cursos Pedagógicos por parte dos candidatos, que deveriam ser ex-alunos de cursos técnicos ou de mestria com experiência na indústria. Segundo esse autor, a exigência do "prévio estágio" trouxe inconvenientes, pois dificilmente um rapaz "já trabalhando" voltava aos bancos escolares.

\section{CONSIDERAÇÕES FINAIS}

No período aqui abordado, a Escola Normal de Artes e Ofícios Wenceslau Brás e a Escola Técnica Nacional eram consideras as "únicas" escolas que formavam professores para o ensino industrial. A singularidade do título foi garantida pela não concretização das demais escolas normais industriais, que após árduas discussões não tiveram seus projetos aprovados, ou quando eram aprovados, não chegaram a funcionar regularmente, como, por exemplo, o projeto de uma Escola Normal Nacional de Arte Aplicada, proposto por Rui Barbosa (em 1882) e a Escola Normal Feminina de Artes e Ofícios (1931-1933), em Araraquara no estado de São Paulo.

A formação de professores na rede federal de ensino profissionalizante era permeada pelos conhecimentos referentes à Matemática, ao Desenho, às Técnicas de Ofício, à Psicologia na Educação e às questões pedagógicas referentes ao ensino.

A relevância da Matemática e do Desenho na formação do professor do ensino industrial também podia ser percebida na distinção do critério de admissão dos candidatos aprovados no Curso Pedagógico de Didática para o Ensino Industrial e no Curso Avulso. O primeiro considerava que o candidato com formação e experiência profissional era detentor da aplicação matemática e do desenho em seu ofício, no outro, o candidato sem a formação técnica adequada, deveria aprender tais conhecimentos, para aplicar de maneira correta nas atividades técnicas. Entretanto, para ser considerado um professor de disciplinas técnicas qualificado era necessária a formação pedagógica, que o diferenciava de um instrutor.

\section{REFERÊNCIAS}

ASSIS, M. M. A. Matemáticas Elementares na Escola

Normal de Natal: legislação, programas de ensino, material didático (1908-1970). 2016. $224 \mathrm{f}$. Tese (Doutorado em
Educação) - Programa de Pós-Graduação em Educação, Universidade Federal do Rio Grande do Norte, 2016.

BOLETIM DA CBAI. Rio de Janeiro (DF), v. 4, n. 12, p. 572, maio 1950.

BOLETIM DA CBAI. Rio de Janeiro/DF, v. 5, n. 5, p. 653-655, maio 1951.

BOLETIM DA CBAI. Rio de Janeiro/DF, v. 6, n. 10, p.912-916, out. 1952.

BRASIL. Decreto de criação da Escola Normal. 1835.

BRASIL. Decreto no 7.566. Criação das Escolas de Aprendizes e Artífices. 1909.

BRASIL. Decreto no 4.073. Lei Orgânica do Ensino Industrial. 1942.

BRASIL. Decreto no 8.680. Dispõe sobre os Cursos Pedagógicos de Ensino Industrial e seu funcionamento. 1954.

CARDOSO, T. F. L. A formação docente na Escola de Artes e Ofícios Wenceslau Braz (1917-1934). In: CONGRESSO BRASILEIRO DE HISTÓRIA DA EDUCAÇÃO, 1., 2000, Rio de Janeiro. Anais [...]. Rio de Janeiro: SBHE, 2000. p. XX-XX.

CARDOSO, T. F. L. O papel social da Escola Normal de Artes e Ofícios Wenceslau Braz. In: SIMPÓSIO NACIONAL DE HISTÓRIA, 23., 2005, Londrina. Anais [...]. Londrina: ANPUH, 2005. p. 1-7.

CARDOSO, T. F. L. Uma escola normal, uma "escola de trabalho". Revista Contemporânea de Educação, Rio de Janeiro, v. 8, n. 15, p. 59-72, jan./jul. 2013.

CELESTE FO. M. Os conflitos na Escola Normal de Piracicaba na década de 1930. História da Educação (Online), Porto Alegre, v. 20, n. 48, p. 213-233, 2016. https:// doi.org/10.1590/2236-3459/52821

CEFETRJ. CEFET/RJ seu tempo e sua história: 90 anos de formação profissional. Rio de Janeiro: O Centro 2007. Doado pelo Arquivo Geral do CEFETRJ. Rio de Janeiro/Brasil.

CIAVATTA, M.; SILVEIRA, Z. S. da. Celso Suckow da Fonseca. Recife: Massangana, 2010.

CUNHA, L. A. O ensino de ofícios nos primórdios da industrialização. São Paulo: UNESP, Brasília, DF: Flacso, 2000a.

CUNHA, L. A. O ensino industrial-manufatureiro no Brasil. Revista Brasileira de Educação, Rio de Janeiro, n. 14, p. 89-193, 2000.

ESCOLA TÉCNICA NACIONAL (ETN). O Brasil precisa de professores - 1960 (cartaz). Arquivo Geral. Fundo ETN, cx. 61.2.2. Rio de Janeiro: Arquivo do CEFETRJ. 
FONSECA, C. S. História do ensino industrial no Brasil. Rio de Janeiro: [s.n.], 1961.

KULESZA, W. A. A institucionalização da Escola Normal no Brasil (1870-1910). Revista Brasileira de Estudos Pedagógicos, Brasília, v. 79 n. 193, p. 63-71, 1998.

MACHADO, L. R. S. Formação de professores para a educação profissional e tecnológica: perspectivas históricas e desafios contemporâneos. In: FORMAÇÃO DE PROFESSORES PARA EDUCAÇÃO PROFISSIONAL E TECNOLÓGICA: Brasília, 26, 27 e 28 de setembro de 2006. Anais [...]. Brasília: Instituto Nacional de Estudos e Pesquisas Educacionais Anísio Teixeira, 2008.

MENESES FILHO, A.; COSTA, M. A. Formação de professores para a educação profissional e tecnológica: o olhar da legislação (1917-2017). In: COLÓQUIO NACIONAL, 4.; COLÓQUIO INTERNACIONAL, 1., 2017. Local. Anais [...]. Tema: A produção do Conhecimento em Educação Profissional. p. 1-12. Disponível em: https://ead.ifrn.edu.br/ coloquio/anais/2017/trabalhos/eixo3/E3A3.pdf. Acesso em: 13 mar. 2019.

MOURA, E. C. M. O Ensino de Matemática em duas escolas profissionalizantes: Brasil e Portugal, no período de 1942 a 1978. 2016. Tese (Doutorado em Educação Matemática) - Programa de Pós-graduação em Educação Matemática, Universidade Estadual Paulista "Júlio de Mesquita Filho", Rio Claro, 2016.

MOURA, E. C. M.; BRITO, A. J. Desenho técnico: uma análise ergológica na formação do técnico brasileiro. In: CONGRESSO IBEROAMERICANO DE EDUCACIÓN MATEMÁTICA, 8., 2017, Madrid. Atas [...]. Madrid, 2017. p. 25-33.

OLIVEIRA, A. S. A formação do professor para a educação profissional: mapeando a produção bibliográfica. 2016. 136 f. Dissertação (Mestrado em Educação) - Programa de Pós-graduação em Educação, Universidade Estadual do Sudoeste da Bahia, Vitória da Conquista, 2016.

OLIVEIRA, M. C. A. Geometria e desenho como matérias do curso normal no período da Primeira República no Brasil. Interfaces Científicas, Aracaju, v. 3, n. 2, p. 43-54, 2015. https://doi.org/10.17564/2316-3828.2015v3n2 p43-54

PORTELA, M. S. Escola Normal: o projeto das elites brasileiras para a formação de professores. 2009. Dissertação (Mestrado em Educação) - Programa de Pós-Graduação em Educação, Pontifícia Universidade Católica do Paraná, Curitiba, 2009.

RHEINHEIMER, J. M. Ensinar e aprender Matemática, ressonâncias da Escola Nova: um olhar sobre a formação de professores no Instituto de Educação General Flores da Cunha (1940-1955). 2018. 203 f. Dissertação (Mestrado em Ensino de Matemática) - Programa de Pós-Graduação em Ensino de Matemática, Universidade Federal do Rio Grande do Sul, 2018.
SOARES F. S. O ensino de matemática na Escola Normal da Corte (1876-1889). Revista HISTEDBR On-line, Campinas, n. 54, p. 128-143, 2013. https://doi.org/10.20396/rho. v13i54.8640173

SOUZA, C. O ensino de matemática na Escola Normal de Belém entre 1950-1970: fragmentos de história. $2015.115 \mathrm{f}$. Dissertação (Mestrado em Educação) - Programa de PósGraduação em Educação em Ciências e Matemáticas, Universidade Federal do Pará, Belém, 2015. https://doi. org/10.18542/amazrecm.v12i23.2427

SOUZA, F. C. S.; RODRIGUES, I. S. Formação de professores para educação profissional no Brasil: percurso histórico e desafios contemporâneos. Revista HISTEDBR On-line, Campinas, v. 17, n. 2 [72], p. 621-638, abr./jun. 2017. https://doi.org/10.20396/rho.v17i2.8644682

URBANETZ, S. T. Uma ilustre desconhecida: a formação docente para a educação profissional. Revista Diálogo Educacional, Curitiba, v. 12, n. 37, p. 863-883, set./dez. 2012. https://doi.org/10.7213/dialogo.educ. 7207

VAITKUNAS, A. D. A industrialização brasileira: da Primeira Guerra Mundial à crise de 1929. 2017. $101 \mathrm{f}$. Dissertação (Mestrado em História Econômica) - Programa de Pós-Graduação em História Econômica, Universidade de São Paulo, São Paulo, 2017.

Recebido em: 11/42019.

Aprovado em: 3/6/2019.

Publicado em: 8/11/2019.

Endereço para correspondência:

Arlete de Jesus Brito

Rua Quirino de Andrade, 215 - Centro

01049-010, São Paulo, SP, Brasil

\footnotetext{
Autoras:

Arlete de Jesus Brito

Doutora pela Faculdade de Educação da Universidade Estadual de Campinas UNICAMP, Campinas SP, Brasil. Professora Livre Docente em História e Educação Matemática, pela Universidade Estadual Paulista - UNESP, São Paulo, SP, Brasil. Possui pós-doutorado pela Universidade de Bielefeld, Alemanha (2009). Atualmente é professora da Universidade Estadual Paulista - Júlio de Mesquita Filho (UNESP), São Paulo, SP, Brasil e líder do grupo de pesquisa História, Filosofia e Educação Matemática (HIFEM)

Orcid: http://orcid.org/0000-0003-1220-7474

E-mail: arlete@rc.unesp.br

Elmha Coelho Moura

Doutora pela Universidade Estadual Paulista- UNESP, Rio Claro, SP, Brasil, no Programa de Educação Matemática-PPEGEM, linha de pesquisa Relações entre História e Educação Matemática, doutorado sanduíche em Portugal pela Universidade Nova de Lisboa, mestrado pela Universidade Estadual PaulistaUNESP, Rio Claro, SP, Brasil no mesmo Programa e linha de pesquisa citados. Membro do grupo de pesquisa História e Filosofia em Educação Matemática (HIFEM), Graduação em Licenciatura Plena em Matemática pela Universidade Federal de Mato Grosso, Cuiabá, MT, Brasil. Professora da Universidade Federal da Integração Latino-Americana (UNILA), Foz do Iguaçu, PR, Brasil. Orcid: http://orcid.org/0000-0001-9345-4236

E-mail: elmhacoelho@gmail.com
} 